\title{
The Effects of Self-Focus On Affect and Vertical Jump Performance of NCAA Athletes
}

\author{
Thomas G. Hammond (Corresponding author) \\ Deakin University, School of Psychology \\ 221 Burwood Higway, Burwood Victoria, Australia, 3125 \\ E-mail: thomas.hammond@deakin.edu.au \\ Henry (Hap) Davis IV \\ Swimming Canada \\ Gulf Canada Square, Suite 354, 401 - 9th Avenue SW \\ Calgary, AB, Canada, T2P 3C5 \\ E-mail: hapdavis@gmail.com \\ Leonard Ziachowsky \\ Boston University, School of Education \\ Two Silber Way, Boston, MA, USA, 02215 \\ E-mail: sport@bu.edu
}

Received: 10-03- 2015

doi:10.7575/aiac.ijkss.v.3n.2p.9
Accepted: 20-04- 2015

Published: $30-04-2015$

URL: http://dx.doi.org/10.7575/aiac.ijkss.v.3n.2p.9

\begin{abstract}
Self-focused attention is often associated with a process of evaluation that has implications for affect, motivation and performance. However, this topic has received little attention in elite sport. Thus, the aim of this study was to understand the relationship between self-focused attention, affective responses and physical performance of successfully $(\mathrm{n}=12)$ and unsuccessful $(\mathrm{n}=12)$ NCAA athletes. Each athlete was presented with a self-focused and otherfocused condition. They provided ratings of positive affect and then completed vertical squat jumps after each stimulus condition. Significant interactions were observed between stimulus condition and athlete performance group for all dependent variables. Successful athletes demonstrated significantly more positive affect, and greater jump height and energy output following the self-focused condition. The opposite trend was observed for unsuccessful athletes. These findings highlight the potential for self-focused attention to enhance or detract from sport performance based on the direction of self-discrepancies.
\end{abstract}

Keywords: self-focused attention, self-evaluation, elite athletes, positive affect, athletic performance

\section{Introduction}

Self-awareness is a complex idea that involves generating a mental abstraction of the self and the consideration of thoughts and experiences in comparison to a set of personal standards (Carver, 2003; Silvia and Phillips, 2013). Through this process the individual directs attention inwards making them and their subjective internal experiences the object of consciousness (Silvia and Duval, 2001). This not only increases awareness but also triggers a process of personal evaluation that has important implications on affective responses, motivation and performance (Silvia and Phillips, 2013).

Objective self-awareness theory (Duval and Wicklund, 1972) suggests that self-focused attention induces an evaluation of the real self to established expectations or an ideal self in a specific domain. Based on this assessment discrepancies between the real self and expectations may exist. If the current situation surpasses expectations then positive affect is experienced. Alternatively, if standards are not being met then negative affect is experienced (Duval and Wicklund, 1972). This discrepancy also plays a role in motivation. If the individual perceives they have the ability to achieve their goal they will attempt to reduce the discrepancy. However, if discrepancy reduction is unlikely, engagement in that particular domain will be avoided (Carver and Scheier, 1981; Silva and Duval, 2001).

Evidence to support the process of self-focused attention, evaluation and affective response has been well established (Silvia and Phillips, 2013). For instance, incongruent self-evaluations have been frequently associated with anxiety and negative affect (Woody and Rodriguez, 2000; Ingram 1990) and threaten self-esteem (Bardel, Fontayne, Colombel and Schiphof, 2010). Alternatively, highly congruent self-focused conditions have been shown to increase performance, persistence and effort on reaction time or cognitive based tasks (Gendolla and Richter, 2010; Gendolla, Richter and 
Silvia, 2008; Panayiotou and Vrana, 2004), and increase the use of attribution strategies to reduce discrepancy between the self and actual performance (Duval and Lalwani, 1999).

This literature suggests self-focused attention is frequently associated with evaluations of individual performances in valued life domains. One context that is constantly concerned with performance evaluation is that of elite sport. Here athletes devote a considerable amount of their life to ensure they are physically and mentally prepared to achieve specific performance standards and goals (Gould and Maynard, 2009; Greenleaf, Gould and Dieffenbach, 2001). Unsurprisingly, they experience a tremendous amount of pressure to maintain or exceed standards (Parham, 1993). Given this emphasis, there would likely be an important relationship between self-focused attention and athlete behaviour.

Within the sport psychology literature, self-focused attention has been associated with performance anxiety and choking (Oudejans, Kuijpers, Kooijman and Bakker, 2011). For example, increased attention to internal processes may result in the conscious and specific monitoring of a motor skill, interfering with task execution (Jackson, Ashford and Norsworthy, 2006). However, not all self-focused attention exerts a negative influence on sport performance. In fact, visual self-processing strategies like imagery are frequently employed to enhance sport performance through various affective and motivational functions (Martin, Moritz and Hall, 1999). Like other forms of self-perception, mental imagery is an internal psychological activity that elicits conscious poly-sensory experiences of objects perceived in the past or may occur in the future (Hall, 2001; Vealey and Greenleaf, 2001).

Within cognitive sport psychology, athletes employ imagery for various functions, such as improving motivation and sport performance (Hall, Mack, Paivio and Hausenblas, 1998; Paivio, 1985). Creating images recalling past performances or imagining the achievement of personal goals have been associated with increased effort and future goal setting (Hall, 2001; Hall et al., 1998). The use of performance imagery has been associated with neural changes (Davis et al., 2008; Davis et al., 2012) that are consistent with strategies that induce self-focused attention (Ma and Han, 2011; Qin and Northoff, 2009).

As with other forms of self-focused attention, imagery is hypothesised to include a process of evaluation. The images generated are believed to cue comparisons between the imagined representations and actual performances (Hall, 2001). The result of which may serve to facilitate performance or potentially detract from it, dependent on a positive or negative discrepancy. However no know studies have directly evaluated this hypothesis.

Preliminary evidence exists to support the idea that self-focused imagery use by athletes may precipitate personal evaluations that alter psychological and physiological conditions conducive for sport performance. For example, when presented with self-referenced stimuli and asked to image a past performance, successful athletes report more positive affect, less negative affect and increased blood oxygen-level dependent (BOLD) activation in the right premotor cortex, sensorimotor cortex (Davis et al., 2012). Conversely, less successful athletes experience less positive affect, more negative affect, and significant reductions in BOLD activity in the motor cortex (Davis et al., 2012), ventromedial prefrontal cortex and para-hippocampus, mirroring a depressed state (Davis et al., 2008).

Based on these findings it is logical to suggest that, consistent with self-awareness theory, the imagery evoked an evaluative process creating positive or negative discrepancies between the self and performance (Carver and Scheier, 1981; Silva and Duval, 2001). Successful athletes likely experience a positive discrepancy that may facilitate future performance. However, unsuccessful athletes likely experienced a negative discrepancy that undoubtedly would hinder performance.

The aim of this study was to directly test this proposition. As a result, two main hypotheses were developed. The first was that during the self-focused condition, successful athletes would report more positive affect, and greater jump height and energy output when compared to their unsuccessful peers. The second hypothesis suggested that following the other-focused condition successful athletes would display decreased positive affect and jump performance. Conversely, unsuccessful athletes would demonstrate increased affect and jump performance.

\section{Method}

\subsection{Participants}

The study sample consisted of 11 male and 13 female athletes $(n=24)$ who competed in swimming $(n=14)$ or athletics $(\mathrm{n}=10)$ at the NCAA level. Participants were aged 18.57 to 24.83 years, with a mean age of 20.42 years $( \pm 1.75)$. All athletes had at least eight years of competitive experience and trained more than 18 hours each week, for at least 35 weeks of a year. Athletes were classified into performance groups as being successful $(\mathrm{n}=12)$ or unsuccessful $(\mathrm{n}=12)$ at a recent major competition. This was based on whether or not the athlete achieved their specific performance goal, as indicated by the respective head coach. This study received ethics approval from the University Review Board and informed consent was obtained from all participants prior to their involvement in the project.

\subsection{Procedure}

Prior to engaging in the test protocol, participants completed a DSM-IV-based psychological interview to screen for the presence of depression. No athlete was diagnosed with a mood disorder and none was medicated for a depression. This screen was undertaken to rule out the potential for a mood disorder that would confound the findings. Following this assessment athletes completed baseline squat jumps. 
After the baseline testing was completed the athletes were presented with self-focused or other-focused condition that consisted of a word and imagery stimulus. The word stimulus was created using 48 positive adjectives (e.g. confident, focused) and 48 negative adjectives (e.g. tense, inferior) generated from the MRC psycholinguistic database of the

University of Western Australia. Based on athlete ratings, using a scale of 1 (not very descriptive of me) to 7 (very descriptive of me), adjectives were selected at random from those with the highest ratings. The imagery stimulus was created using athlete photos taken prior to a competition that were edited to appear on the university newspaper.

Over the course of each condition, athletes were asked to rate their level of positive affect at two points in time. The presentation of these stimuli was counterbalanced so that half of the sample group received the self or other condition first. Subsequent to each stimulus, athletes were then asked to complete a vertical squat jump. This procedure was repeated for a total of two trials.

\subsection{Stimulus Condition}

During the self-focused condition athletes were presented with a photo of themselves taken prior to a competition (35 seconds). Then, a set of self-descriptive adjectives was displayed under the photo. The athletes were asked to consider what adjective described them best. Following a distractor cue the athletes were then again presented with their selfphoto. They were instructed to think about their performance and imagine what was happening in the photo (35 seconds). Over the course of the 90 -second stimuli, athletes provided a verbal rating of positive affect at two points in time.

The other-focused stimulus was analogous to the self-focus task. The athletes were presented with a photo of an unknown athlete in the same sport. They were then asked to consider this athlete and a list of neutral descriptive adjectives. After a distractor cue the participants were shown the same athlete photo and were asked to imagine this person performing their sport. Two verbal affect ratings were also collected.

\subsection{Jump Performance}

To perform the squat jump, athletes were coached to align their feet shoulder width apart, while keeping their heels on the ground. They were instructed to bend their knees at 90 degrees and place hands on their hips to minimize counter movement (Van Soest and Bobbert, 1993; Rabahi et al., 2013). Then, athletes were asked to jump as high as possible (Rabahi et al., 2013). Two trials were performed in each test condition (self-focused, other-focused attention) for a total of four squat jumps.

\subsection{Measures}

The height and power of each jump were calculated using the OPTOJUMP apparatus (Microgate, Bolzano, Italy). This is an optical acquisition system consists of two bars, arranged in parallel, containing light emitting diodes positioned 0.3 cm from ground level (Castagna, et al., 2011; Glatthorn et al., 2013; Rabahi et al., 2013). This system allows for the measurement of ground contact and flight time, from which jump height $(\mathrm{cm})$ and energy output $(\mathrm{J} / \mathrm{kg})$ is calculated (see Castagna, et al., 2011). This method has demonstrated good convergent validity with force platforms, which, are considered as the gold standard for measuring flight times (Castagna, et al., 2011; Glatthorn et al., 2013) and good testretest reliability (Glatthorn et al., 2013). Following the completion of the physical performance, jump height and energy scores observed in each test condition were then converted to the average percent change from baseline.

Positive affect was measured at two points in time during the presentation of each stimulus, for a total of four ratings in each condition. Athletes were asked to rate their level of happiness using a 7-point scale with anchors of no happiness (1) to complete happiness (7). Happiness represents a combination of pleasure and activation within the circumplex model of affect (Russell, 1980; 2003), thus providing a good indication of overall positive affect. Mean affect scores were then calculated based on the four ratings collected from each imagery condition.

\subsection{Data Analysis}

Initially, the data were checked to determine if they represented a normal distribution of scores using the KolmogorovSmirnov statistic. All variables were non-significant, indicating no departures from normality. The Durbin-Watson statistic (d) was used to test for auto-correlations. The values obtained for each regression were above the upper and lower critical values $(\mathrm{dl}=0.74, \mathrm{du}=1.03$; Savin and White, 1977), revealing no evidence of auto-correlations. This suggests that the errors are independent of each other and thus conducive for linear analyses (Tabachnick and Fidell, 2007).

Following these procedures, descriptive statistics were calculated for all variables. Chi-square values were then calculated to ensure that gender and sport type were approximately equal in each performance group. Baseline jump height and energy output were also evaluated for potential differences between groups using independent t-tests prior to the imagery stimuli. To test for potential differences in the dependent variables between imagery condition and athlete group, mixed ANOVAs were conducted. To further evaluate the models observed, additional t-tests were completed.

\section{Results}

\subsection{Baseline}

Prior to the completion of the test protocol no significant differences in gender $\left(\chi_{1,24}^{2}=.17, P=.68\right)$ or sport discipline $\left(\chi_{1,24}^{2}=.69, P=.41\right)$, squat jump height $\left(t_{22}=-.60, P=.55\right)$ or squat jump energy output $\left(t_{22}=-.59, P=.56\right)$ were 
observed between the successful and unsuccessful athletes. Thus, the two groups were comparable at baseline (see Table 1). No baseline affect data was available for comparison.

Table 1. Baseline Descriptive Statistics

\begin{tabular}{ccc}
\hline \multicolumn{1}{c}{ Variable } & Successful Athletes & Unsuccessful Athletes \\
\hline Gender (n) & 5 & 6 \\
Male & 7 & 6 \\
\multicolumn{1}{c}{ Female } & & \\
Sport (n) & 6 & 4 \\
Athletics & 6 & 8 \\
Swimming & $25.61 \pm 5.74$ & $27.12 \pm 6.38$ \\
Mean Squat Jump Height $(\mathrm{cm})$ & $2.51 \pm .56$ & $2.65 \pm .62$ \\
Mean Squat Jump Energy $(\mathrm{J} / \mathrm{kg})$ &
\end{tabular}

\subsection{Positive Affect}

The results showed a significant interaction effect between athlete group and stimulus condition on positive affect $\left(F_{1,22}\right.$ $=4.63, P=.04$, partial eta $\left.^{2}=.17\right)$. To further explore this interaction, follow-up analyses showed that unsuccessful athletes displayed significantly less positive affect across both stimulus conditions compared to their successful peers (see Figure 1). Interestingly, unsuccessful athletes reported more positive affect during the other-focused condition compared to the self-focused condition however, this difference was not significant. Among successful athletes, significantly greater positive affect was observed following the self-focused condition compared to the other-focused condition $\left(t_{11}=4.29, P<.01\right.$, eta $\left.^{2}=.65\right)$.

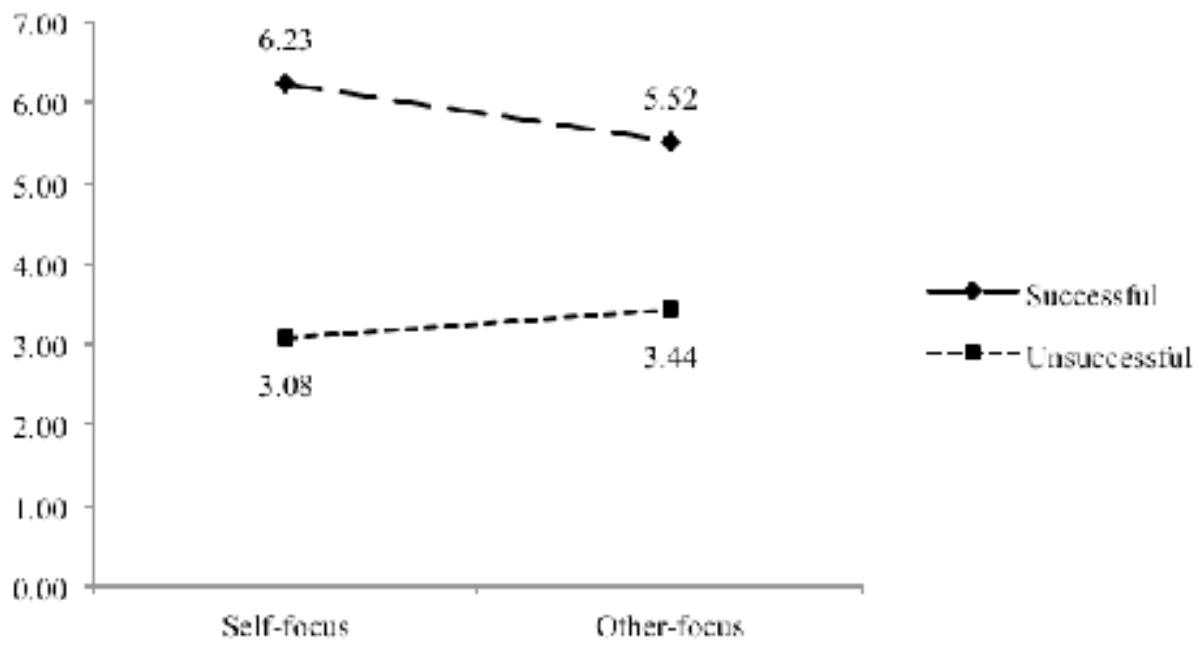

Figure 1. Plot of interaction effect between athlete group and stimulus condition for positive affect

Description: Unsuccessful athletes reported significantly lower affect scores following the self-focused $\left(\mathrm{t}_{22}=5.90, \mathrm{P}<\right.$ .01 eta $\left.^{2}=.61\right)$ and other-focused imagery conditions $\left(\mathrm{t}_{22}=3.49, \mathrm{P}<.01\right.$, eta $\left.^{2}=.35\right)$.

\subsection{Jump Performance}

Two mixed ANOVAs were completed to examine the effects of the independent variables on jump height and energy output, as a measure of sport performance. Assumptions of sphericity and homogeneity of variance were each met. The results of the first mixed ANOVA indicated that there was a significant, and large interaction effect $\left(F_{1,22}=4.37, P<\right.$ .05 , partial eta ${ }^{2}=.17$ ) between athlete group and stimulus condition on jump height. As shown in Figure 2 , successful athletes showed an increase from baseline in jump height following the self-focused and other-focused conditions, whilst unsuccessful athletes showed a marked decrease.

To further evaluate this interaction, additional analyses showed that unsuccessful athletes showed a significantly greater decrease in jump height following the self-focus condition when compared to their successful peers $\left(t_{22}=2.31, P=.03\right.$, eta $\left.^{2}=.19\right)$. No significant differences were observed between athletes groups following the other-focused condition, which may have been due to a lack of power associated with a small sample size. As illustrated by Figure 2, within the 
unsuccessful athlete group, there was a greater decrease in jump height following the self-focused condition than the other-focused condition $\left(t_{11}=-2.37, P=.03\right.$, eta $\left.^{2}=.34\right)$.

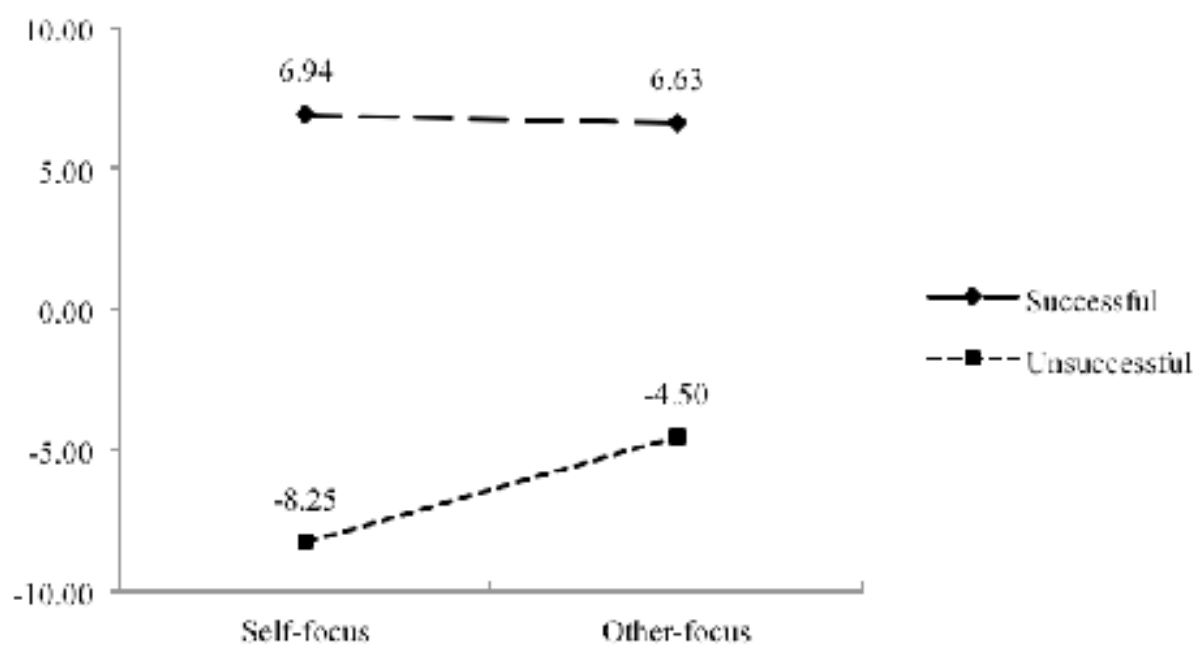

Figure 2. Plot of interaction effect between athlete group and stimulus condition for $\%$ change from baseline in jump height

Consistent with the above, the result of the second mixed ANOVA was essentially identical. A significant interaction effect between the independent variables was observed when considering jump energy $\left(F_{1,22}=4.39, P<.05\right.$, partial eta $\left.^{2}=.16\right)$. As displayed in Table 2, unsuccessful athletes experienced a significant percentage decrease from baseline in energy output following the self-focused condition compared to their successful peers, who showed an increase from baseline. Between conditions, unsuccessful athletes again showed significant greater decline in energy output $\left[t_{11}=-\right.$ $2.36, P=.03, \mathrm{eta}^{2}=.33$ ] following the self-focused condition than following the other-focused condition.

Table 2. Comparison of $\%$ change from baseline in jump energy output by stimulus condition and athlete group

\begin{tabular}{|c|c|c|c|c|c|}
\hline & $\begin{array}{l}\text { Successful Athletes } \\
\qquad \underline{\mathrm{N}=12} \\
\text { Mean }\end{array}$ & $\begin{array}{l}\text { Unsuccessful } \\
\text { Athletes } \\
\frac{\mathrm{N}=12}{\text { Mean }}\end{array}$ & $t$ & $P$ & eta $^{2}$ \\
\hline \multicolumn{6}{|l|}{ Jump Energy } \\
\hline Self-Focused & $+6.91 \pm 15.65$ & $-8.24 \pm 16.61$ & 2.30 & .03 & .19 \\
\hline Other-Focused & $+6.58 \pm 16.58$ & $-4.47 \pm 16.47$ & 1.64 & .12 & .11 \\
\hline
\end{tabular}

\section{Discussion}

Self-focused attention is a process that not only increases personal awareness but also is associated with personal evaluation (Silvia and Phillips, 2013). Here, the self is contrasted with personal expectations, which may influence a number of factors including, affect, motivation, and future performance (Duval and Lalwani, 1999; Gendolla and Richter, 2010; Woody and Rodriguez, 2000). As with other forms of self-focused attention, imagery employed in sport contexts also includes a process of self-evaluation (Hall, 2001). The aim of this study was to assess the implications of this process on the affective responses and sport performance of elite athletes.

The initial hypotheses suggested that following the self-focused condition successful athletes would display more positive affect and greater jump performance. The results confirmed this hypothesis. When self-focused attention was induced, successful athletes reported significantly more positive affect and displayed greater jump height and energy output when compared to a group unsuccessful athletes.

These findings were anticipated given the previous literature where successful athletes presented with self-referenced stimuli have been shown to report more positive affect and less negative affect than their unsuccessful peers (Davis et al., 2008; Davis et al., 2012). As proposed in objective self-awareness theory, such affective responses are likely the result of discrepancies between the real and ideal self (Carver and Scheier, 1981; Silva and Duval, 2001). In this case, self-focused attention induced a process of evaluation, where successful athletes perceived congruency between the self, adjectives, and imagery scenario, resulting in more positive affect. 
Furthermore, self-focused stimuli that evoke the perception of congruency between the self and personal standards have been associated with enhanced performance on cognitive based and reaction time tasks (Gendolla and Richter, 2010; Gendolla, et al., 2008; Panayiotou and Vrana, 2004). However, this study extends these findings to sport performance.

Predictably, the unsuccessful athlete group demonstrated significantly less positive affect and a negative change in jump performance following the presentation of the self-focused stimulus. This observation suggests that self-focused attention created a powerful negative discrepancy, perhaps, focused on past failures and personal expectations that hindered performance (Silvia and Phillips, 2013). Stemming from this evaluative process the negative change in jump height and energy may have manifest through diminished motivation (Carver and Scheier, 1981; Silva and Duval, 2001) and decreased activation in the motor cortex (Davis et al., 2012).

In summary, the self-focused condition was associated with significant differences in positive affect and jump performance between successful and unsuccessful athletes. In accordance with self-awareness theory this may have been due to positive and negative discrepancies between the self and personal expectations.

The second hypothesis proposed that the other-focused condition would be associated with a reduction in positive affect and jump performance for successful athletes while the opposite trend would be observed among the unsuccessful athletes. This was based on the notion that perceiving the athlete would not evoke the same high level of self-evaluation associated with the self-focused stimulus (Ma and Han, 2011; Qin and Northoff, 2009). The results partially supported this proposition.

After viewing the other-focused condition, the successful athlete group reported significantly less positive affect but no changes were noted in jump performance. In respect to unsuccessful athletes, significantly higher jump height and energy output were observed, however, no change in affect was occurred. Given these findings it is suggested that the other-focused condition, concentrated on perceiving another athlete, may not have evoked the same level of selfevaluation associated with direct self-focused attention.

As demonstrated in physiological studies, the perception of another has been associated with decreased BOLD activation in the medial prefrontal cortex that appears uniquely associated with perception of self (Ma and Han, 2011; Qin and Northoff, 2009). Thus, the athletes did not likely form as robust discrepancies, in a positive or negative direction, between the self, other and personal expectations, diminishing the potential influence on affect and jump performance.

Based on these findings, evoking self-focused attention may result in affective differences and act to facilitate or hinder the performance of motor skills. The direction may depend on whether the stimulus generates a positive or negative discrepancy based on personal expectation. In the case of successful athletes, recalling images of past performances likely cued past efficacious performances, which may have confirmed or exceeded expectations. The opposite is likely true for unsuccessful athletes. Ultimately, the increase or decrease in energy output of large muscle groups involved in the majority of sports would have implications on overall sport performance and perhaps perpetuate future discrepancies between the self and expectations.

From this perspective it is recommended that practitioners take caution when evoking self-focused attention for the purposes of performance enhancement. For example, when developing imagery scripts, it would be important to avoid scenarios that trigger negative discrepancies between the self and expectations. Rather the focus should be on creating scenarios that confirm or enhance positive discrepancies or act to develop personal efficacy during difficult situations (Hammond, Gregg, Hrycaiko, Mactavish, and Leslie-Toogood, 2012).

It is also recommended that cognitive strategies be included to augment the process of self-focused attention. As previously demonstrated, the use of cognitive restructuring can lessen the negative effects of self-focused attention for unsuccessful athletes and direct focus to skill development (Davis et al., 2008). Additionally, the inclusion of mindfulness may also provide positive assistance by focusing on specific aspects of the image rather than diverting to a natural process of judgment and evaluation (Kabat-Zinn, 1990).

Although this study presented a novel perspective on the use of self-focused attention in elite sport, several limitations have been identified for consideration in future research. For example, baseline affect scores were not collected from each athlete group. Thus, it is difficult to determine the effect of each test condition on positive affect. It is recommended future studies include this assessment.

Additionally, it may have been more informative to consider additional variables like negative affect and self-esteem, which may have shown a strong association to the imagery condition and jump performance. The inclusion of a selfconsciousness scale may also have provided subjective insights into the degree of self-focus each athlete possessed, which may play a role in the overall effect of the stimuli. Finally, this study included a small sample of NCAA athletes who competed in swimming and athletics; follow-up studies should be conducted to evaluate the generalizability of findings.

In summary, this study attempted to understand the relationship between self-focus, affective responses, and jump performance of elite athletes. Among recently successful athletes, it was observed that a self-focused stimulus was associated with positive affect and greater improvements in the jump performance relative to an other-focused condition. The opposite trend was observed among unsuccessful athletes, who displayed a negative change in jump performance and less positive affect following a self-focused condition. This may have been due to the development of 
discrepancies between the self and personal expectations that either facilitated or hindered performance. It is suggested that practitioners avoid scenarios that trigger negative discrepancies and focus on those that confirm positive discrepancies or act to develop personal efficacy during difficult situations.

\section{References}

Bardel, M. H., Fontayne, P., Colombel, F., and Schiphof, L. (2010). Effects of match result and social comparison on sport state self-esteem fluctuations. Psychology of Sport and Exercise, 11, 171-176.

Carver C.S. (2003). Self-awareness. In M. R. Leary and J. P. Tangney (Eds), Handbook of self and identity (p. 179196). New York: Guilford Press.

Carver C. S., and Scheier, M. F. (1981). Attention and self-regulation. New York: Springer.

Castagna, C., Ganzetti, M., Ditroilo, M., Giovannelli, M., Rocchetti, A., and Manzi, V. (2013). Concurrent validity of vertical jump performance assessment systems. The Journal of Strength and Conditioning Research, 27, 761-768.

Davis IV, H., van Anders, S. M., Ngan, E. T., Woodward, T. S., Van Snellenberg, J. X., Mayberg, H. S., and Liotti, M. (2012). Neural, mood, and endocrine responses in elite athletes relative to successful and failed performance videos. Journal of Clinical Sport Psychology, 6, 6-21.

Davis IV, H., Liotti, M., Ngan, E. T., Woodward, T. S., Van Snellenberg, J. X., van Anders, S. M., ... and Mayberg, H. S. (2008). fMRI BOLD signal changes in elite swimmers while viewing videos of personal failure. Brain Imaging and Behavior, 2, 84-93.

Duval, T. S., and Wicklund, R. A. (1972). A theory of objective self-awareness. New York: Academic Press.

Duval, T. S., and Lalwani, N. (1999). Objective self-awareness and causal attributions for self-standard discrepancies: Changing self or changing standards of correctness. Personality and Social Psychology Bulletin, 25, 1220-1229.

Gendolla, G. H., and Richter, M. (2010). Effort mobilization when the self is involved: Some lessons from the cardiovascular system. Review of General Psychology, 14, 212-225.

Gendolla, G. H. E., Richter, M., and Silvia, P. J. (2008). Self-focus and task difficulty effects on cardiovascular reactivity. Psychophysiology, 45, 653-662.

Gould, D., and Maynard, I. (2009). Psychological preparation for the Olympic Games. Journal of Sports Sciences, 27, 1393-1408.

Glatthorn, J. F., Gouge, S., Nussbaumer, S., Stauffacher, S., Impellizzeri, F. M., and Maffiuletti, N. A. (2011). Validity and reliability of Optojump photoelectric cells for estimating vertical jump height. The Journal of Strength and Conditioning Research, 25, 556-560.

Greenleaf, C., Gould, D., and Dieffenbach, K. (2001). Factors influencing Olympic performance: interviews with Atlanta and Negano US Olympians. Journal of Applied Sport Psychology, 13, 154-184.

Hall, C. (2001). Imagery in sport and exercise. In R.N. Singer, H.A. Hausenblas, and C.M. Janelle (Eds.), Handbook of sport psychology (2 $2^{\text {nd }}$ ed., pp.529-549). New York: John Wiley and Sons.

Hall, C., Mack, D., Paivio, A. and Hausenblas, H. (1998) Imagery use by athletes: Development of the sport imagery questionnaire. International Journal of Sport Psychology, 29, 73-89.

Hammond, T., Gregg, M., Hrycaiko, D., Mactavish, J., and Leslie-Toogood, A. (2012). The effects of a motivational general-mastery imagery intervention on the imagery ability and sport confidence of inter-collegiate golfers. Journal of Imagery Research in Sport and Physical Activity, 7(1). doi: 10.1515/1932-0191.1066

Ingram, R. (1990). Self-focused attention in clinical disorders: Review and a conceptual model. Psychological Bulletin, 107, 156-176.

Jackson, R.C., Ashford, K.J., and Norsworthy, G. (2006). Attentional focus, dispositional reinvestment, and skilled motor performance under pressure. Journal of Sport and Exercise Psychology, 28, 49-68.

Kabat-Zinn, J. (1990). Full catastrophe living: Using the wisdom of your body and mind to face stress, pain and illness. New York: Delta Trade.

Ma, Y., and Han, S. (2011). Neural representation of self-concept in sighted and congenitally blind adults. Brain, 134, 235-246.

Martin, K., Moritz, S. and Hall, C. (1999). Imagery use in sport: A literature review and applied model. The sport Psychologist, 13, 245-268.

Oudejans, R. R., Kuijpers, W., Kooijman, C. C., and Bakker, F. C. (2011). Thoughts and attention of athletes under pressure: skill-focus or performance worries?. Anxiety, Stress, and Coping, 24, 59-73.

Panayiotou, G., and Vrana, S. R. (2004). The role of self-focus, task difficulty, task self-relevance, and evaluation anxiety in reaction time performance. Motivation and Emotion, 28, 171-196.

Parham, W.D. (1993). The intercollegiate athlete: A 1990s profile. Counselling Psychology, 21, 411-429. 
Paivio, A. (1985). Cognitive and motivational functions of imagery in human performance. Canadian Journal of Sport Sciences, 10, 24-28.

Qin, P., and Northoff, G. (2011). How is our self related to midline regions and the default-mode network? Neuroimage, 57, 1221-1233.

Rabahi, T., Fargier, P., Sarraj, A. R., Clouzeau, C., and Massarelli, R. (2013). Effect of Action verbs on the performance of a complex movement. PloS one, 8, doi: 10.1371/journal.pone.0068687

Russell, J.A. (1980). A circumplex model of affect. Journal of Personality and Social Psychology, 39, 1161-1178.

Russell, J.A. (2003). Core affect and the psychological construction of emotion. Psychological Review, 110, $145-172$.

Savin, N.E., and White, K.J. (1977). The Durbin-Watson test for serial correlation with extreme sample sizes or many regressors. Econometrica: Journal of the Econometric Society, 45, 1989-1996

Silvia, P. J., and Duval, T. S. (2001). Objective self-awareness theory: Recent progress and enduring problems. Personality and Social Psychology Review, 5, 230-241.

Silvia, P. J., and Phillips, A. G. (2013). Self-awareness without awareness? Implicit self focused attention and behavioral self-regulation. Self and Identity, 12, 114-127.

Tabachnick B., Fidell L.S. (2007). Using Multivariate Statistics $5^{\text {th }}$ edition. Boston: Pearson.

Vealey, R. S. and Greenleaf, C. A. (2001). Seeing is believing: Understanding and using imagery in sport. In J. M. Williams (Ed.), Applied sport psychology: Personal growth to peak performance, $5^{\text {th }}$ ed. (pp. 306-348). Mountain View, CA: Mayfield.

Woody, S. R., and Rodriguez, B. F. (2000). Self-focused attention and social anxiety in social phobics and normal controls. Cognitive Therapy and Research, 24, 473-488.

\section{Note}

1. No funding or conflicts of interest to declare. 